\title{
ANALISIS USAHA TERASI UDANG DI DESA TAMBAKLEKOK KABUPATEN PASURUAN
}

\author{
Analysis Of Shrimp Paste BusinessIn Tambaklekok Village Pasuruan Regency
}

\author{
Zaini Musthofa* dan Roisatul Ainiyah \\ Program Studi Teknologi Hasil Perikanan, Fakultas Pertanian,Universitas Yudharta Pasuruan \\ *Penulis korespondesi, email: zaenmusthafa@gmail.com
}

\begin{abstract}
Potential of marine and fishery of Pasuruan Regency covers sea territory which reaches about $48 \mathrm{~km}$ starting from Nguling, Lekok, Rejoso, and Bangil Subdistricts. Tambaklekok Village is a coastal village in Lekok sub-district, Pasuruan regency, known as a place for processing fishery products, such as fish crackers, fish chips, fish pets, salted fish, smoked fish, shrimp paste, and others. Shrimp paste has high economic value, Tambaklekok Villagers whose livelihoods as fishermen reach $45 \%$ of the total population, and there are only 5 (five) heads of households who have business making shrimp paste. This indicates that Tambaklekok area has potential for the development of shrimp paste making business. The purpose of this study is to analyze the potential feasibility of making shrimp paste in Tambaklekok Village. The method used in this study is a case study, by approaching through observation, interviews, and questionnaires. The business feasibility analysis is done by price production approach, Break Even Point (BEP), R/C Ratio (Return Cost of Ratio), B/C Ratio (Benefit Cost of Ratio).The results of the financial analysis it is known that from the calculation of the average $R / C$ ratio and $B / C$ ratio, which can determine the feasibility of the shrimp paste business in Tambaklekok Village. It is known that the shrimp paste business gets a B/C ratio $<1$ that is 0.82 . This shows that the shrimp paste business in Tambaklekok Village is not feasible. However, if according to the $R / C$ ratio criteria, the $R / C$ ratio $>1$ is equal to 1.82 . This shows that the shrimp paste business in Tambaklekok Village can be said to be feasible to continue and develop.These results indicate the calculation of the average value of the $R / C$ ratio, the shrimp paste business in Tambaklekok Village is in the profitable category and deserves to continue.
\end{abstract}

Keywords: Tambaklekok Village, shrimp paste, financial analysis, feasibility

\begin{abstract}
ABSTRAK
Potensi kelautan dan perikanan Kabupaten Pasuruan meliputi wilayah perairan laut yang mencapai sekitar $48 \mathrm{~km}$ mulai Kecamatan Nguling, Lekok, Rejoso, hingga Bangil. Desa Tambaklekok merupakan desa pesisir di Kecamatan Lekok Kabupaten Pasuruan, dikenal sebagai tempat pengolahan hasil perikanan, seperti kerupuk ikan, keripik ikan, petis ikan, ikan asin, ikan asap, terasi, dan lain-lain. Terasi memiliki nilai ekonomis tinggi. Penduduk Desa Tambaklekok yang mata pencaharian sebagai nelayan mencapai $45 \%$ dari jumlah total penduduk, dan hanya ada 5 (lima) kepala keluarga yang memiliki usaha pembuatan terasi. Hal ini mengindikasikan wilayah Tambaklekok berpotensi bagi pengembangan usaha pembuatan terasi.Tujuan dari penelitian ini adalah menganalisis potensi kelayakan usaha pembuatan terasi udang di Desa Tambaklekok. Metode yang digunakan dalam penelitian ini adalah studi kasus, dengan melakukan pendekatan melalui observasi, wawancara, dan kuesioner. Analisis kelayakan usaha dilakukan dengan pendekatan harga produksi, Break Even Point (BEP), R/C Ratio (Return Cost of Ratio), B/C Ratio (Benefit Cost of Ratio).Hasil analisis finansial diketahui bahwa dari perhitungan rata-rata nilai $\mathrm{R} / \mathrm{C}$ ratio dan $\mathrm{B} / \mathrm{C}$ ratio, yang dapat menentukan kelayakan usaha terasi di Desa Tambaklekok. Diketahui bahwa usaha terasi mendapat nilai B/C ratio < 1 yaitu 0,82 . Hal ini menunjukkan bahwa usaha terasi di Desa Tambaklekok tidak layak dijalankan. Namun, jika menurut kriteria $\mathrm{R} / \mathrm{C}$ ratio, nilai $\mathrm{R} / \mathrm{C}$ ratio $>1$ yaitu sebesar 1,82 . Hal ini menunjukkan usaha terasi di Desa Tambaklekok dapat dikatakan layak untuk dilanjutkan dan
\end{abstract}


dikembangkan.Hasil tersebut menunjukan perhitungan rata-rata nilai $\mathrm{R} / \mathrm{C}$ ratio, usaha terasi di Desa Tambaklekok termasuk kategori menguntungkan dan layak dilanjutkan.

Kata Kunci: Desa Tambaklekok, terasi, analisis finansial, kelayakan

\section{PENDAHULUAN}

\section{Latar Belakang}

Indonesia memiliki potensi besar dalam peningkatan pemanfaatan usaha pada sektor perikanan. Sektor perikanan merupakan salah satu bagian dari rencana pembangunan nasional yang dilaksanakan secara kontinyu dan bertahap. Pembangunan perikanan bukan hanya pada usaha peningkatan produksi perikanan, namun juga terhadap pendapatan, peningkatan taraf hidup para nelayan, dan petani ikan. Maka diperlukan upaya untuk mengembangkan usaha perikanan dengan memperhatikan analisis finansial dalam sektor perikanan (Pantow et al, 2016). Salah satu daerah yang memiliki potensi untuk mewujudkan upaya tersebut yaitu Kabupaten Pasuruan.

Potensi kelautan dan perikanan Kabupaten Pasuruan meliputi wilayah perairan laut yang mencapai sekitar $48 \mathrm{~km}$ mulai Kecamatan Nguling, Lekok, Rejoso, hingga Bangil. Desa Tambaklekok merupakan desa pesisir di Kecamatan Lekok Kabupaten Pasuruan, dikenal sebagai tempat pengolahan hasil perikanan, seperti kerupuk ikan, keripik ikan, petis ikan, ikan asin, ikan asap, terasi, dan lain-lain.

Terasi memiliki nilai ekonomis tinggi, pengolahan terasi sudah banyak dilakukan oleh masyarakat di kawasan pesisir sebagai kegiatan sampingan dalam peningkatan pendapatan ekonomi keluarga dan juga turut berpartisipasi dalam upaya pembangunan nasional dalam sektor perikanan. Kondisi tersebut memungkinkan sektor kelautan dan perikanan dapat meningkatkan taraf hidup masyarakat.

Berdasarkan observasi dan wawancara terhadap salah satu aparatur Desa Tambaklekok, penduduk yang mata pencahariannya sebagai nelayan mencapai $45 \%$ dari jumlah total penduduk, dan baru ada 5 (lima) kepala keluarga yang memiliki usaha pembuatan terasi, hal ini mengindikasikan wilayah Tambaklekok berpotensi bagi pengembangan usaha pembuatan terasi. Oleh sebab itu perlu adanya kajian lebih lanjut dan peneliti merasa perlu melakukan penelitian mengenai usaha pembuatan terasi dengan judul "Analisis Usaha Perikanan Terasi Udang di Desa Tambaklekok Kabupaten Pasuruan".Rumusan masalah adalah Bagaimana analisis kelayakan usaha dan sanitasi hygiene dalam pembuatan terasi udang di Desa Tambaklekok?. Tujuan penelitian ini yaitu untuk mengetahui kelayakan usaha pembuatan terasi udang di Desa Tambaklekok, dan menyediakan informasi kepada responden untuk pengembangan usaha pembuatan terasi udang di Desa Tambaklekok.

\section{METODOLOGI PENELITIAN}

Penelitian ini menggunakan metode studi kasus. Studi kasus merupakan kajian yang mendalami suatu kasus, lingkungan, dan situasi tertentu dengan mengungkap atau memahami suatu hal (Toariaunaldi, 2017).

\section{Waktu dan Tempat}

Penelitian ini dilaksanakan mulai dari bulan Februari 2018 sampai Juli 2018 di unit usaha pembuatan terasi udang Desa Tambaklekok Kabupaten Pasuruan.

\section{Penentuan Responden}

Responden dalam penelitian ini
adalah pemilik usaha terasi desa Tambaklekok. Metode pengambilan responden menggunakan sensus, metode sensus merupakan pengumpulan data yang diambil dari keseluruhan populasi dan diselidiki satu persatu. Adapun jumlah responden yang 
diambil berjumlah 5 orang pemilik usaha pembuatan terasi.

\section{Pengumpulan Data}

Dalam penelitian ini data yang digunakan terdiri dari data primer dan data sekunder. Data primer diperoleh langsung dari sumber penelitian melalui beberapa kegiatan, antara lain:

a. Observasi: pengumpulan data melalui pengamatan secara langsung terkait usaha terasi udang di Desa Tambaklekok.

b. Wawancara: pengumpulan data dengan cara kegiatan tanya-jawab langsung dengan pemilik usaha terasi.

c. Dokumentasi; data yang diperoleh dalam bentuk tertulis berupa pustaka mengenai desa Tambaklekok.

d. Kuesioner; teknik pengumpulan data melalui pengisian kuesioner oleh pemilik usaha terasi.

Sedangkan data sekunder diperoleh secara tidak langsung serta penunjang data primer melalui studi pustaka dan lembaga pemerintahan berupa jumlah penduduk, letak geografis, dan hal-hal terkait dengan penelitian ini.

\section{Analisis Data}

Semua data yang dikumpulkan akan dianalisis secara deskriptif kualitatif, dan deskriptif kuantitatif berdasarkan aspek yang diperoleh dari hasil observasi, wawancara, dan pengisian kuesiner oleh responden.

1. Teknik Produksi

Analisis teknis dilakukan dengan deskriptif, yaitu menggambarkan kegiatan usaha pembuatan terasi Desa Tambaklekok, meliputi peralatan dan hasil produksi.

2. Pasar/Pemasaran

Peluang pasar merupakan penentu dari minat konsumen terhadap produk. Jika peluang tehadap hasil perikanan masih terbuka maka usaha terasi dapat diterima oleh konsumen atau pasar.

3. Izin Hukum
Suatu usaha pembuatan terasi layak dilaksanakan dan dikembangkan jika telah memiliki izin hukum dari pihak pemerintah, misal dari Dinas Perdagangan Daerah atau Dinas Kesehatan.

4. Kondisi Sosial Ekonomi Responden Masri (2010) dalam Ningsih (2013) mengemukakan, dalam menganalisis data kondisi sosial ekonomi digunakan analisis deskriptif untuk menggambarkan karakteristik dan mengetahui keterkaitan antar berbagai variabel dengan kondisi usaha pembuatan terasi.

5. Aspek Finansial

\section{Penerimaan dan Pendapatan}

Untuk mengetahui total penerimaan usaha pembuatan terasi dapat dihitung dengan menggunakan rumus:

$$
\mathbf{T R}=\mathbf{P} \cdot \mathbf{Q}
$$

Ket: $\quad$ TR $=$ Total Penerimaan

$$
\begin{array}{ll}
\mathrm{P} & =\text { Harga Jual Produk } / \mathrm{kg} \\
\mathrm{Q} & =\text { Total Produksi }(\mathrm{kg})
\end{array}
$$

Untuk mengetahui total pendapatan bersih dari usaha terasi dapat dihitung menggunakan rumus:

$$
\mathbf{I}=\mathbf{T R}-\mathbf{T C}
$$

$$
\begin{aligned}
& \text { Ket: } \mathrm{I} \quad=\text { Pendapatan/Input } \\
& \text { TR = Total Penerimaan } \\
& \text { TC = Total Cost/Biaya Total }
\end{aligned}
$$

\section{Analisis Kelayakan}

\section{Break Event Point (BEP)}

BEP merupakan titik impas dari suatu usaha. Menurut Maulidah (2012), BEP adalah suatu keadaan dimana perusahaan dalam operasinya tidak memperoleh laba dan juga tidak menderita kerugian dengan kata lain total biaya sama dengan total penjualan sehingga tidak ada laba dan rugi. Rumus BEP sebagai berikut:

$$
\mathbf{B E P}_{\text {produksi }}=\frac{\mathrm{TC}}{\mathbf{P}}
$$




$$
\mathbf{B E P}_{\text {harga }}=\frac{\mathbf{T C}}{\mathbf{Q}}
$$

Ket:BEP = Break Event Point (Titik Impas)

$\mathrm{TC}=$ Total Cost (Biaya Total)

$\mathrm{P} \quad=$ Harga Jual Produk $/ \mathrm{Kg}$

$\mathrm{Q} \quad=$ Total Produksi $(\mathrm{Kg})$

\section{Analisis Perubahan Harga}

Rumus yang digunakan dalam perhitungan analisis perubahan harga yaitu:

\section{Perubahan HargA}

$$
=100 \%-\left(\frac{\text { BEP }_{\text {harga }}}{\text { Harga Rill }} x 100 \%\right)
$$

Ket: BEP_harga = Harga Saat BEP

Harga Rill = Harga Saat Penelitian

\section{Return Cost of Ratio (R/C Ratio)}

$\mathrm{R} / \mathrm{C}$ ratio merupakan syarat utama untuk menentukan kelayakan suatu usaha. Menurut Soekartawi (1995) dalam Maulidah (2012), efisiensi dalam pekerjaan merupakan perbandingan terbaik suatu pekerjaan dengan hasil yang diperoleh dari pekerjaan tersebut. Perbandingan tersebut dapat dilihat dari:

a. Segi Hasil, apabila suatu usaha dapat diperoleh hasil maksimal, baik dalam hal kualitas maupun kuantitasnya maka pekerjaan tersebut dikatakan efisien.

b. Usaha, suatu pekerjaan dikatakan efisien jika hasil tertentu dapat dicapai dengan usaha yang minimal.

Tingkat efisiensi suatu usaha bisa ditentukan dengan menghitung per cost ratio yaitu imbangan antara hasil usaha dengan total biaya produksinya, dan dapat diukur menggunakan analisis $\mathrm{R} / \mathrm{C}$ ratio (Soekartawi 1995 dalam Maulidah 2012).

Adapun kriteria hasil dalam analisis $\mathrm{R} / \mathrm{C}$ ratio sebagai berikut:

a. R/C ratio $>1$, maka usaha layak dan menguntungkan

b. $\mathrm{R} / \mathrm{C}$ ratio $=1$, usaha tersebut $\mathrm{BEP}$ c. $\mathrm{R} / \mathrm{C}$ ratio $<1$, usaha tidak efisien atau merugikan

d. Rumus analisis $\mathrm{R} / \mathrm{C}$ ratio, yaitu:

Ket:

$$
\mathrm{R} / \mathrm{C}_{\text {ratio }}=\frac{\mathrm{TR}}{\mathrm{TC}}
$$

$\mathrm{R} / \mathrm{C}$ ratio $=$ Return Cost of Ratio

TR $=$ Total Penerimaan

TC $=$ Total Cost

\section{B/C Ratio (Benefit Cost of Ratio)}

Menurut Maulidah (2012), B/C ratio merupakan penilaian untuk melihat tingkat efisiensi penggunaan biaya, dalam analisis $\mathrm{B} / \mathrm{C}$ ratio data yang diutamakan adalah besarnya manfaat yang didapat. Kriteria ini memberikan pedoman bahwa suatu proyek akan dipilih apabila nilai $\mathrm{B} / \mathrm{C}$ ratio $>1$. Namun sebaliknya, apabila nilai B/C ratio < 1, maka proyek tidak akan diterima.

Ningsih (2013), mengemukakan kriteria yang dapat diperoleh dari perhitungan $\mathrm{B} / \mathrm{C}$ ratio antara lain:

a. $\mathrm{B} / \mathrm{C}$ ratio > 1, maka usaha menguntungkan

b. $\mathrm{B} / \mathrm{C}$ ratio $=1$, usaha tidak menguntungkan dan tidak merugikan

c. $\mathrm{B} / \mathrm{C}$ ratio $<1$, usaha merugikan

Adapun rumus $\mathrm{B} / \mathrm{C}$ ratio sebagai berikut:

Ket:

$$
=\frac{\mathrm{I}_{\text {ratio }}}{\mathrm{TC}} \times \mathbf{1 0 0} \%
$$

$\begin{array}{ll}\mathrm{B} / \mathrm{C} \text { ratio } & =\text { Benefit Cost of Ratio } \\ \mathrm{I} & =\text { Total Pendapatan } \\ \mathrm{TC} & =\text { Total Cost }\end{array}$

\section{HASIL DAN PEMBAHASAN}

Desa Tambaklekok termasuk dalam wilayah Kecamatan Lekok Kabupaten Pasuruan yang berada di ujung pesisir utara Lekok. Desa Tambaklekok terdiri dari 10 (Sepuluh) dusun, yaitu: Dusun Batu Ampar, Krajan, Kampung Baru Timur, Kampung Baru Barat, Sanggaran Timur, Sanggaran Barat, Porangan, Bong Tengah Barat, Bong Tengah Timur, dan Pasirian. Adapun Pusat 
Pemerintahan Desa Tambaklekok terletak di dusun Batu Ampar RT 001/RW 001. Ditinjau dari segi geografis terletak pada batas-batas sebagai berikut:

$\begin{array}{ll}\text { a. Sebelah Utara } & \text { :Selat Madura } \\ \text { b. Sebelah Timur } & \text { :Desa Jatirejo }\end{array}$ Kecamatan Lekok

c. Sebelah Selatan :Desa Segoropuro Kecamatan Rejoso

d. Sebelah Barat :Desa Patuguran Kecamatan Rejoso

Wilayah Desa Tambaklekok terletak pada dataran rendah koordinat antara 2 meter dari dataran tinggi dengan luas \pm 609.09 ha dengan jumlah total penduduk sebanyak 6133 jiwa terdiri dari laki-laki 2990 jiwa dan perempuan 3143 jiwa. Mata pencaharian penduduk cukup beragam yaitu pada bidang perikanan, pertanian, industri, perdagangan, angkutan, dan jasa lainnya. Akan tetapi mayoritas penduduk Desa Tambaklekok bermata pencaharian sebagai nelayan. Jumlah nelayan mencapai $45 \%$ dari jumlah total penduduk desa (RPJM Desa Tambaklekok, 2016).

Hasil tangkapan para nelayan juga beraneka ragam jenis perikanan misal jenis hasil tangkapannya adalah ikan kembung, teri, bawal putih, tembang, tongkol, cakalang, belanak, kepiting, rajungan, cumicumi, kerang, udang rebon, dan lain-lain. Udang rebon ini yang nantinya dijadikan bahan baku dari usaha pembuatan terasi. Usaha terasi di wilayah ini masih menjadi sampingan. Selain peralatan yang masih sederhana, tenaga kerja dilakukan anggota keluarga sendiri, dan masih ada 5 keluarga yang menjalankan usaha pembuatan terasi.

\section{Analisis Non Finansial}

a. Teknik Produksi

Pelaku usaha pembuatan terasi di Desa Tambaklekok dalam melakukan kegiatan produksi terasi yaitu dengan menggunakan peralatan tradisional, meskipun pada zaman modern ini sudah ada peralatan yang lebih canggih, misal penggiling terasi dan sebagainya. Namun dengan peralatan yang ada tidak menghambat pelaku usaha pembuatan terasi di Desa Tambaklekok untuk tetap produktif dan juga tidak mengurangi minat konsumen terhadap produk yang dihasilkan oleh para pemilik usaha terasi.

Di dalam proses pengolahannya, usaha pembuatan terasi di Desa Tambaklekok sudah mengupayakan beberapa tindakan dan prinsip dari sanitasi, misalnya membuang sumber kontaminan pada bahan seperti kotoran yang masih menempel di lapisan permukaan kulit, pencucian bahan dan alat dengan menggunakan air bersih. Akan tetapi masih ada tindakan yang belum sesuai sanitasi dan hygiene, misalnya kebersihan dan kesehatan pekerja yang belum terjamin, tindakan pengemasan yang belum sesuai dengan persyaratan standar.

\section{b. Izin Hukum Usaha}

Setiap usaha pada dasarnya dikatakan layak jika usaha tersebut sudah memiliki izin usaha dari Dinas Pemerintah terkait, sebagai jaminan akan produk yang dihasilkan. Dalam sebuah usaha minimal sudah memiliki Perizinan Industri Rumah Tangga (P-IRT). Belum ada perizinan minimal dalam usaha terasi di Desa Tambaklekok, hal ini dikarenakan tidak adanya pengaruh peraturan hukum pemerintah terhadap kesadaran pemilik usaha akan pentingnya perizinan hukum usaha.

\section{c. Karakteristik Responden}

Karakteristik responden dapat dibedakan berdasarkan beberapa hal yang bertujuan untuk mengetahui ciri identitas responden satu dengan yang lain, yaitu:

1. Jenis Kelamin

Dalam penelitian ini responden berjumlah 5 orang pemilik usaha terasi. Berdasarkan pengisian kuesioner oleh responden pemilik usaha pembuatan terasi terdiri dari 2 laki-laki dan 3 perempuan yaitu Syairi (A), Samsudin (B), Siti Shoimah (C), Hj. Karsinah (D), dan Hj. Pujiyah (E). Berdasarkan hasil produksi yang dihasilkan setiap responden, usaha terasi pemilik perempuan lebih produktif dari pada lakilaki. Hal tersebut disebabkan oleh 
perempuan memiliki waktu lebih untuk memproduksi terasi.

2. Umur

Umur adalah hal yang mempengaruhi kemampuan mempelajari, memahami dan peningkatan produktivitas kerja seseorang. Rata-rata umur pemilik usaha terasi Desa Tambaklekok 50 tahun. Umur minimal pemilik usaha terasi yaitu 30 tahun dan umur maksimal pemilik usaha terasi adalah 60 tahun. Pada dasarnya usia muda lebih produktif dalam menjalankan usaha, namun dalam menjalankan usaha terasi di Desa Tambaklekok usia tua tidak menutup kemungkinan lebih produktif dibandingkan usia muda.

3. Jenjang Pendidikan

Menurut Ningsih (2013), pendidikan merupakan suatu parameter yang dapat menentukan perkembangan dan kemajuan suatu usaha yang dijalankan. Semakin tinggi pendidikan, semakin besar pengaruh teknologi dalam mengembangkan usaha. Tingkat pendidikan pemilik usaha terasi Desa Tambaklekok masih rendah, rata-rata masih tingkat Sekolah Dasar (SD). Hal ini berpengaruh terhadap pekembangan dan kemajuan usaha. Akan tetapi, dengan pendidikan rendah pemilik berusaha sebaik mungkin dalam menjalankan usaha agar tetap bisa bersaing dengan usaha-usaha yang memiliki teknologi modern, meskipun dengan menggunakan peralatan tradisional.

4. Lama Usaha
Rata-rata pemilik usaha terasi Desa Tambaklekok berdasarkan pengisian kuesioner pengalaman lama berusaha sudah lebih dari 10 tahun. Namun ada juga pemilik yang masih baru 3 tahun dalam menjalankan usaha pembuatan terasi. Pengalaman lama usaha berpengaruh terhadap produktifitas usaha terasi di Desa Tambaklekok, semakin lama pengalaman usaha pemilik, semakin menambah tingkat produktifitas usaha terasi yang dijalankan.

\section{Analisis Finansial}

Berdasarkan aspek finansial usaha terasi di Desa Tambaklekok yang dilakukan dapat diketahui dengan menggunakan perhitungan analisis BEP, perubahan harga, $\mathrm{R} / \mathrm{C}$ ratio, dan $\mathrm{B} / \mathrm{C}$ ratio. Hasil perhitungan analisis $\mathrm{BEP}$, perubahan harga, $\mathrm{R} / \mathrm{C}$ ratio, dan $\mathrm{B} / \mathrm{C}$ ratio dengan hasil sebagai berikut pada Tabel 1.

Setiap responden memiliki tingkat kelayakan usahanya sendiri. Berdasarkan perhitungan rata-rata analisis $\mathrm{R} / \mathrm{C}$ ratio dan $\mathrm{B} / \mathrm{C}$ ratio, yang dapat menentukan kelayakan usaha terasi di Desa Tambaklekok. Diketahui dari Tabel 4.2 bahwa usaha terasi mendapat nilai $\mathrm{B} / \mathrm{C}$ ratio $<1$ yaitu 0,82 . Hal ini menunjukkan bahwa usaha terasi di Desa Tambaklekok tidak layak dijalankan. Namun, jika menurut kriteria $\mathrm{R} / \mathrm{C}$ ratio, nilai $\mathrm{R} / \mathrm{C}$ ratio $>1$ yaitu sebesar 1,82. Hal ini menunjukkan usaha terasi di Desa Tambaklekok dapat dikatakan layak untuk dilanjutkan dan dikembangkan.

Tabel 1. Hasil Analisis Finansial 


\begin{tabular}{|c|c|c|c|c|c|c|}
\hline Komponen & Pemilik 'A' & Pemilik 'B' & Pemilik 'C' & Pemilik 'D' & Pemilik 'E' & $\begin{array}{l}\text { Rata- } \\
\text { rata }\end{array}$ \\
\hline \multicolumn{7}{|l|}{ Permodalan } \\
\hline $\begin{array}{l}\text { Biaya } \\
\text { variabel }\end{array}$ & Rp.474.000,- & $\begin{array}{c}\text { Rp.162.000, } \\
-\end{array}$ & Rp.624.000,- & $\begin{array}{c}\text { Rp.408.000, } \\
-\end{array}$ & $\begin{array}{c}\text { Rp.245.000, } \\
-\end{array}$ & \\
\hline Biaya tetap & Rp.10.000,- & Rp.10.000,- & Rp.10.000,- & Rp.7.500,- & Rp.35.000,- & \\
\hline $\begin{array}{l}\text { Total biaya } \\
\text { (TC) }\end{array}$ & Rp.484.000,- & $\begin{array}{c}\text { Rp.172.000, } \\
-\end{array}$ & Rp.634.000,- & $\begin{array}{c}\text { Rp.415.500, } \\
-\end{array}$ & $\begin{array}{c}\text { Rp.280.000, } \\
-\end{array}$ & \\
\hline \multicolumn{7}{|l|}{ Produk } \\
\hline Banyak (Q) & $17 \mathrm{Kg}$ & $3 \mathrm{Kg}$ & $25 \mathrm{Kg}$ & $5 \mathrm{Kg}$ & $5 \mathrm{Kg}$ & \\
\hline $\begin{array}{l}\text { Harga/Kg } \\
\text { (P) }\end{array}$ & Rp.70.000,- & Rp.70.000,- & Rp.70.000,- & $\begin{array}{c}\text { Rp.120.000, } \\
-\end{array}$ & Rp.70.000,- & \\
\hline $\begin{array}{l}\text { Penerimaan } \\
\text { (TR) }\end{array}$ & $\begin{array}{c}\text { Rp.1.190.000, } \\
-\end{array}$ & $\begin{array}{c}\text { Rp.210.000, } \\
-\end{array}$ & $\begin{array}{c}\text { Rp.1.750.000, } \\
-\end{array}$ & $\begin{array}{c}\text { Rp.600.000, } \\
-\end{array}$ & $\begin{array}{c}\text { Rp.350.000, } \\
-\end{array}$ & \\
\hline $\begin{array}{l}\text { Pendapatan } \\
\text { (I) }\end{array}$ & Rp.706.000,- & Rp.38.000,- & $\begin{array}{c}\text { Rp.1.116.000, } \\
-\end{array}$ & $\begin{array}{c}\text { Rp.184.500, } \\
-\end{array}$ & Rp.70.000,- & \\
\hline \multicolumn{7}{|c|}{ Analisis Kelayakan } \\
\hline $\begin{array}{l}\text { BEP } \\
\text { produksi }\end{array}$ & $6,91 \mathrm{Kg}$ & $2,45 \mathrm{Kg}$ & $9,0 \mathrm{Kg}$ & $3,46 \mathrm{Kg}$ & $4 \mathrm{Kg}$ & \\
\hline $\begin{array}{l}\mathrm{BEP} \\
\text { harga/Kg }\end{array}$ & Rp.28.470,- & Rp.57.333,- & Rp.25.360,- & Rp.83,100,- & Rp.56.000,- & \\
\hline $\begin{array}{l}\text { Perubahan } \\
\text { harga }\end{array}$ & $0,59 \%$ & $0,18 \%$ & $0,63 \%$ & $0,3 \%$ & $0,2 \%$ & \\
\hline $\mathrm{B} / \mathrm{C}$ ratio & 1,45 & 0,22 & 1,76 & 0,44 & 0,25 & 0,82 \\
\hline $\mathrm{R} / \mathrm{C}$ ratio & 2,45 & 1,22 & 2,76 & 1,44 & 1,25 & 1,82 \\
\hline
\end{tabular}

Sumber: Data Diolah

\section{.KESIMPULAN DAN SARAN}

\section{Kesimpulan}

Berdasarkan rumasan masalah dan hasil pembahasan diperoleh perhitungan rata-rata nilai $\mathrm{R} / \mathrm{C}$ ratio usaha terasi di Desa Tambaklekok termasuk kategori menguntungkan dan layak dilanjutkan. Proses pembuatan terasi di Desa Tambaklekok masih belum sesuai dengan persyaratan keamanan pangan sanitasi hygiene.

\section{Saran}

Berdasarkan kesimpulan yang diperoleh, maka saran yang dapat disampaikan adalah sebagai berikut:

1. Pemilik usaha terasi di Desa Tambaklekok diharapkan menambah keterampilan dalam hal produksi, misal dengan menggunakan mesin penggiling dan sebagainya.

2. Diharapkan dapat meningkatkan hasil produksi dengan menambah jumlah bahan baku agar dapat menambah penerimaan serta pendapatan dan usaha layak untuk dijalankan.

3. Melakukan kegiatan promosi agar menambah luas pasar atau peluang serta mengajukan perizinan usaha terhadap pemerintah agar menjamin produk yang dihasilkan.

4. Untuk menghasilkan produk terasi udang dengan kualitas baik di tempat pembuatan terasi Desa Tambaklekok, maka bahan dan peralatan yang digunakan juga harus baik, dan sesuai persyaratan keamanan pangan agar lebih terjamin mutu produk. 
5. Diharapkan ada penelitian lebih lanjut tentang analisis usaha terasi di Desa Tambaklekok ditinjau dari berbagai aspek yang lebih terpadu.

\section{DAFTAR PUSTAKA}

Anonim. (2004). Departemen Kesehatan RI. Tentang Hygiene dan Sanitasi. (http://www.journal.unair.ac.id), diakses 6 Mei 2018.

Indradi, Ismail., Wijayanto, Dian., Yulianto, Taufik., dan Suroto. (2013). Analisis Kelayakan Usaha Perikanan Laut Kabupaten Kendal. Jurnal Saintek Perikanan. Vol. 8 No. 2. 52-56.

Kementerian Pendidikan Nasional. (2010). Pedoman Penulisan Karya Ilmiah: Skripsi, Tesis, Disertasi, Artikel, Makalah, Tugas Akhir, Laporan Penelitian (Edisi Kelima). Malang: Universitas Negeri Malang.

Maflahah, Iffan. (2013). Kajian Potensi Usaha Pembuatan Terasi Udang Studi Kasus Desa Bantelan, Kecamatan Batu Putih, Kabupaten Sumenep. Agrointek. Vol. 7 No. 2. 99-102.

Masri. (2010). Identifikasi Karakteristik Sosial, Ekonomi, dan Budaya Masyarakat Nelayan Sungai Limau di Kabupaten Padang Pariaman dalam Penyediaan Perumahan Pemukiman. Universitas Diponegoro. Semarang.

Maulidah, Silvana. (2012). Pengantar Usaha Tani: Kelayakan Usaha Tani. Universitas Brawijaya. Malang.

Muhibbin, Mokh M. (2017). Analisis Usaha Ternak Ayam Boiler (Studi Kasus di Ternak Ayam Kunto Dewo Dusun Damar Desa Sekarmojo). Skripsi tidak diterbitkan. Pasuruan. Universitas Yudharta Pasuruan.

Nasarudin, Indo Yama. (2013). Analisis Kelayakan Ekonomi dan Keuangan Usaha Ikan Lele Asap di Pekanbaru. Jurnal Etikonomi. Vol. 12 No. 2. 165178.

Ningsih, Rahayu Septia., Mudzakir, A. K. \& Rosyid, Abdul. (2013). Analisis Kelayakan Finansial Usaha Perikanan
Payang Jabur (Boat Seine) di Pelabuhan Perikanan Pantai Asemdoyong Kabupaten Pemalang. Journal of Fisheries Resources Utilization Management and Technology, (Online), Vol. 2 No. 3. 223-232, (http://www.ejournals1.undip.ac.id/index.php/jfrumt), diakses 1 Mei 2018.

Pantow, Julita G.L., Suhaeni, S. \& Wassak, M. (2016). Analisis Usaha Budidaya Ikan Nila pada CV. Tiga Mas di Desa Talawaan Kecamatan Talawaan Kabupaten Minahasa Utara. Akulturasi. Vol. 4 No. 7. 541-548.

Pemerintah Desa Tambaklekok. (2016). Rencana Pembangunan Jangka Menengah Desa Tambaklekok Periode 2016-2021. Pasuruan.

Rahmayati, R., Riyadi, Putut Har. \& Rianingsih, L. (2014). Perbedaan Konsentrasi Garam Terhadap Pembentukan Warna Terasi Udang Rebon (Acetes sp.) Basah. Jurnal Pengolahan dan Bioteknologi Hasil Perikanan, (Online), Vol. 3 No. 1. 108-117, (http://www.ejournals1.undip.ac.id/index.php/jpbhp), diakses 4 Mei 2018.

SNI. (2009). Terasi Udang, Bagian 1: Spesifikasi. Diakses 3 Mei 2018.

SNI. (2009). Terasi Udang, Bagian 2: Persyaratan Bahan Baku. Diakses 3 Mei 2018.

Soekartawi. (1995). Analisis Usahatani. Universitas Indonesia. Jakarta.

Suratiyah, Ken. (2015). Ilmu Usahatani. Penebar Swadaya. Jakarta.

Susilo, Dody., dkk. (2017). Peningkatan Kualitas Sumberdaya dan Pelayanan Sosial di Desa Tambaklekok Kecamatan Lekok Kabupaten Pasuruan. Laporan Kegiatan Pengabdian Kepada Masyarakat (KKN-PPM Berbasis Riset) tidak diterbitkan. Pasuruan. Universitas Yudharta Pasuruan.

Toariaunaldi, Mhd., Hendrik. \& Hamid, H. (2017). Prospek Pengembangan Usaha Terasi di Pelabuhan Perikanan Pantai 
Kuala Tungkal Kabupaten Tanjung Jabung Barat Provinsi Jambi. Universitas Riau.

Undang-Undang RI. (2004). Nomor 31, tentang Perikanan.

Yulia, Miftahul. (2014). Analisis Dampak

Kenaikan Harga Faktor Produksi
Terhadap Usaha Tempe (Studi Kasus: di Desa Ngadimulyo Kecamatan Sukorejo). Skripsi tidak diterbitkan. Pasuruan. Universitas Yudharta Pasuruan. 